\title{
Current trends in targeted therapy for drug-resistant infections
}

\author{
Leila Rahbarnia ${ }^{1}$ (D) Safar Farajnia ${ }^{2} \cdot$ Behrooz Naghili $^{1} \cdot$ Vahideh Ahmadzadeh $^{2} \cdot$ Kamal Veisi $^{3,4}$. \\ Roghayyeh Baghban ${ }^{5}$. Sayna Toraby ${ }^{6}$
}

Received: 11 May 2019 /Revised: 9 July 2019 / Accepted: 12 July 2019 /Published online: 14 August 2019

(C) Springer-Verlag GmbH Germany, part of Springer Nature 2019

\begin{abstract}
Escalating antibiotic resistance is now a serious menace to global public health. It may be led to the emergence of "postantibiotic age" in which most of infections are untreatable. At present, there is an essential need to explore novel therapeutic strategies as a strong and sustainable pipeline to combat antibiotic-resistant infections. This review focuses on recent advances in this area including therapeutic antibodies, antimicrobial peptides, vaccines, gene therapy, genome editing, and phage therapy for tackling drug-resistant infections.
\end{abstract}

Keywords Drug-resistant infections $\cdot$ Antibody $\cdot$ Antimicrobial peptides $\cdot$ Vaccine $\cdot$ Phage therapy $\cdot$ Genome editing

\section{Introduction}

In 1928, the discovery of penicillin by Alexander Fleming revolutionized the treatment of infectious diseases. Thereafter, development of diverse antibiotic classes led to remarkable reduction of morbidity and mortality caused by infections in surgical, transplant, cancer, and critical care patients. Most of antibiotic classes were discovered between 1940 and 1960 years known as the antibiotic golden age (Lewis 2013). However, emergence of antibiotic-resistant infections limited the effectiveness of conventional therapeutic agents (Sievert et al. 2008).

\section{Safar Farajnia}

Farajnias@tbzmed.ac.ir

Leila Rahbarnia

le.rahbarnia@gmail.com

Behrooz Naghili

naghilib@tbzmed.ac.ir

Vahideh Ahmadzadeh

vahideh_ahmadzadeh@yahoo.com

Kamal Veisi

k.veissie@gmail.com

Roghayyeh Baghban

baghbanroghayyeh@yahoo.com

Sayna Toraby

sayna.toraby.7@gmail.com
Based on recent reports, up to 2 million people every year are infected by resistant infections with minimum of 23,000 and 33,000 deaths per year in the USA and European Union, respectively (Cassini et al. 2019., El Chakhtoura et al. 2018). In this respect, it is estimated that near to 10 million deaths will be occurred by multi drug-resistant bacteria by 2050 year (Sierra et al. 2017).

Accordingly, the World Health Organization (WHO) and the Infectious Disease Society of America (IDSA) have introduced antimicrobial resistance as one of the three greatest crises to public health (World Health Organization 2017) (Infectious Diseases Society of America (IDSA) 2011).

1 Infectious and Tropical Diseases Research Center, Tabriz University of Medical Sciences, Tabriz, Iran

2 Drug Applied Research Center, Tabriz University of Medical Sciences, P.O. Box: 51656-65811, Tabriz, Iran

3 Department of Medical Biotechnology, Faculty of Medicine, Kermanshah University of Medical Sciences, Kermanshah, Iran

4 Biotechnology Department, School of Advanced Technologies in Medicine, Shahid Beheshti University of Medical Sciences, Tehran, Iran

5 Biotechnology Research Center, Tabriz University of Medical Sciences, Tabriz, Iran

6 Immunology Research Center, Tabriz, University of Medical Sciences, Tabriz, Iran 
Antimicrobial resistance today has spread to the last line antibiotics such Vancomycin and Colistin (Kumar 2016).

Since antibiotic resistance mechanisms are complicated and production of new antibiotics is time consuming and expensive, development of alternative therapeutic approaches for tackling antimicrobial resistance seems to be essential (Davies and Davies 2010) (Pehrsson et al. 2016).

Although development of new therapeutic approaches such as vaccines, genome editing techniques, antibodies, antimicrobial peptides, small RNAs, and phage therapy have made notable advances in the control of infectious diseases, they are still the third cause of death in the world (Trevisan et al. 2017). This review focuses on recent advances in evolution of novel therapeutic agents against drug-resistant infections.

\section{Vaccine therapy}

Vaccines are biological agents which activate acquired immunity towards infections in a manner similar to pathogens.

The first vaccine was developed almost 200 years ago when Edward Jenner employed cowpox virus to immunize individuals towards smallpox (Riedel 2005). However, the new era in development of vaccine began when Louis Pasteur established the principle of purification and injection of microorganisms to the host to induce immune responses (Kallerup and Foged 2015). During the last century, notable successes were achieved in the field of vaccine development; for instance, the smallpox and rinderpest were eradicated and measles, polio, and tetanus diseases were controlled effectively through vaccination (Greenwood 2014).

Mostly, vaccines are produced from the inactivated or attenuated pathogens, cell surface proteins, or toxin. Bacterial vaccines are commonly created as killed pathogen, while viral vaccines are generated as inactivated viruses. Until now, numerous vaccines have been approved to control viral and bacterial illnesses (Table 1). The common features of all vaccines are specificity, safety, and long-term immunity against pathogen without unwanted immune responses such as hypersensitivity and autoimmunity in host (Vartak and Sucheck 2016). In this respect, different generations of vaccines have been developed to control infectious diseases, including killed and live attenuated vaccines as the first generation, toxoid and subunit vaccines as the second generation, and recombinant and DNA vaccines as third generation vaccines (Pöri and Pinja 2018) (Fig. 1).

\section{Live attenuated vaccines}

As noted above, the attenuated vaccines are viral particles or live bacterial cells with decreased virulence capable to induce immune responses in the host (Clem 2011). There are various approaches to introduce attenuating mutations in pathogens such as serial culture under suboptimal conditions (i.e., low temperature) or non-human hosts (i.e., animal embryo). Hence, based on the host type, the attenuated vaccines created as nerve tissue vaccines, embryonated egg vaccines, and cell culture vaccines. An attenuated vaccine as mimicking the wild-type pathogen can induce a comprehensive immune response including both cellular and humoral immunity with long lived protection (Mak and Saunders 2005).

The smallpox vaccine derived from cowpox was the first viral attenuated vaccine which was developed by Edward Jenner in 1796 (Riedel 2005).

At present, numerous attenuated vaccines have been approved for clinical use. Bacillus Calmette Guérin (BCG) vaccine against tuberculosis (TB), MMR vaccine with trade name Priorix ${ }^{\circledR}$ (including three attenuated viruses measles, mumps, and rubella), FluMist ${ }^{\circledR}$ Quadrivalent against Influenza virus and Zostavax ${ }^{\circledR}$ (Merck \& Co.) towards Herpes Zoster virus (Med Immune, LLC) are examples of successful attenuated live vaccines under clinical use (Ravanfar et al. 2009) (Kallerup and Foged 2015).

However, there are some limitations to employ the attenuated vaccines in patients with immune system disorders or with history of organ transplant (Vartak and Sucheck 2016). Therefore, the modified versions of attenuated vaccines such as killed, subunit, or peptide vaccines have been developed to prevent infection.

\section{Inactivated vaccines}

Inactivated vaccines are the killed version of pathogens resulting from pathogens inactivation by physical (heat) or chemical (formaldehyde) agents so that pathogen can induce immune responses without replication in the host. Although the immunogenicity of inactivated vaccines is lower due to conformational changes of antigens inducing immune responses (Pöri and Pinja 2018), they are extremely safe due to losing the replication ability (Kallerup and Foged 2015). Until now, several inactivated vaccines have been developed and licensed such as Typhoid vaccine, AGRIFLU ${ }^{\circledR}$ as a trivalent vaccine against influenza type A and B viruses, Havrix ${ }^{\circledR}$ (GSK) to prevent Hepatitis A disease and IPOL ${ }^{\circledR}$ (Sanofi Pasteur) that targets Poliovirus (Pöri and Pinja 2018).

\section{Toxoids}

Some bacteria are not directly pathogenic but infection is caused by secretory toxins. For example, tetanus disease is caused by a neurotoxin called Tetanospasmin produced by Clostridium tetani. In such cases, protective immune 
Table 1 List of approved vaccines by 2018 (http://www.immunize.org/timeline/)

Approved vaccine list Year $\quad$ Events

Influenza vaccines

a. Afluria

b. FluMist

c. Fluarix Quadrivalent

d. Fluad

e. Rapivab

f. Fluzone

Hib vaccines (Haemophilus influenzae type b)
a. ActHIB $®$ (Sanofi Pasteur)
b. Pedvax HIB $®$ (Merck)
c. Hiberix ${ }^{\circledR}(\mathrm{GSK})$

DTaP Vaccines (Diphtheria, Tetanus, acellular Pertussis)

a. Daptacel $®$ (Sanofi Pasteur)

b. Infanrix ${ }^{\circledR}(\mathrm{GSK})$

Hepatitis B Vaccines

a. Engerix B $®(\mathrm{GSK})$

b. Recombivax $₫$ (Merck)

c. Dynavax

Hepatitis A Vaccines

a. Vaqta ${ }^{\circledR}$ (Merck)

b. Havrix ${ }^{\circledR}(\mathrm{GSK})$

c. Twinrix

September 28, 2007

September 19, 2007

January 11, 2018

November 24, 2015

December 19, 2014

December 11, 2014

March 1993

Dec 20, 1989

January 14, 2016

Jan 29, 1997

May 14, 2002

July 23, 1986

Aug 28, 1989

November 9, 2017

Feb 22, 1995

Mar 29, 1996

May 11, 2001

June 25, 1963

Polio Vaccine

a. IPOL $®$ (Sanofi Pasteur)

Yellow fever vaccine

a. YF-Vax

Jan 3, 1978

May 22, 1953

June 8, 2006

HPV vaccines (Human Papillomavirus)

a. Gardasil-9® (Merck)

Pneumococcal Vaccines

a. Prevnar 13 ® (Wyeth)

July 1983
Events

FDA approved Afluria, a new inactivated influenza vaccine for use in people age 18 years and older.

FDA approved use of FluMist nasal-spray influenza vaccine in children age $2-5$ years.

FDA approved expanded pediatric age indication for Fluarix Quadrivalent influenza vaccine.

FDA approved new injectable influenza vaccine, Fluad, for use in people age 65 years and older

FDA approved Rapivab to treat influenza infection.

FDA approved quadrivalent formulation of Fluzone Intradermal inactivated influenza vaccine.

Conjugated Haemophilus influenzae type $\mathrm{b}$ vaccines (ActHIB by Connaught/Mérieux and OmniHib by SmithKline Beecham) were licensed.

Conjugated Haemophilus influenzae type b (Hib) vaccine (PedvaxHIB by Merck) was licensed.

FDA approved Hiberix for full Hib vaccine series.

Diphtheria and tetanus toxoids and acellular pertussis vaccine adsorbed (Infanrix by SmithKline Beecham) was licensed for the first four doses of the series.

Diphtheria and tetanus toxoids and acellular pertussis vaccine (Daptacel by Aventis Pasteur) was licensed.

Recombinant hepatitis B vaccine (Recombivax HB by Merck) was licensed.

Recombinant hepatitis B vaccine (Engerix B by SmithKline Beecham) was licensed.

FDA licensed Heplisav-B, the new hepatitis B vaccine from Dynavax, for use in adults age 18 and older.

The first inactivated hepatitis A vaccine (Havrix by SmithKline Beecham) was licensed.

A second inactivated hepatitis A vaccine (Vaqta by Merck) was licensed.

A combined hepatitis A inactivated and hepatitis B (recombinant) vaccine (Twinrix by SmithKline Beecham) was licensed.

Trivalent oral polio vaccine was licensed.

An enhanced-potency inactivated poliovirus vaccine (Ipol by Pasteur Méérieux Vaccins et Serums) was licensed.

Yellow fever vaccine (YF-Vax by Connaught) was licensed in the USA.

Yellow fever vaccine (Merrell National Labs) was first licensed in the USA.

FDA licensed the first vaccine developed to prevent cervical cancer (Gardasil by Merck \& Co., Inc.), precancerous genital lesions, and genital warts due to human papillomavirus (HPV) types 6,11 , 16 , and 18 .

Two enhanced pneumococcal polysaccharide vaccines were licensed (Pneumovax 23 by Merck on July 11 and Pnu-Imune 23 by Lederle on July 21). These vaccines included 23 purified capsular polysaccharide antigens of Streptococcus pneumoniae and replaced the 14-valent polysaccharide vaccine licensed in 1977. 
Table 1 (continued)

\begin{tabular}{|c|c|c|}
\hline Approved vaccine list & Year & Events \\
\hline \multirow{5}{*}{$\begin{array}{l}\text { Meningococcal conjugate vaccines } \\
\text { a. Menactra }{ }^{\circledR} \text { (Sanofi Pasteur) } \\
\text { b. Menveo }{ }^{\circledR} \text { (Novartis) }\end{array}$} & February 24, 2010 & $\begin{array}{l}\text { FDA approved licensure of Pneumococcal } 13 \text {-valent } \\
\text { conjugate vaccine (PCV13), which offers broader } \\
\text { protections against Steptococcus pneumoniae infections. }\end{array}$ \\
\hline & February 24, 2010 & $\begin{array}{l}\text { FDA approved pneumococcal } 13 \text {-valent conjugate } \\
\text { vaccine (Prevnar 13), which offers broader protection } \\
\text { against Streptococcus pneumoniae. }\end{array}$ \\
\hline & January 23, 2015 & $\begin{array}{l}\text { FDA approved the use of Bexsero, the second vaccine } \\
\text { licensed in the USA to prevent serogroup B } \\
\text { meningococcal disease. }\end{array}$ \\
\hline & April 22, 2011 & $\begin{array}{l}\text { FDA approved the first vaccine (Menactra, meningococcal } \\
\text { conjugate vaccine, sanofi pasteur) to prevent } \\
\text { meningococcal disease in infants and toddlers }\end{array}$ \\
\hline & February 19, 2010 & $\begin{array}{l}\text { FDA approved licensure of Menveo (Novartis), } \\
\text { meningococcal conjugate vaccine for people } \\
\text { ages } 11 \text { through } 55 \text { years. }\end{array}$ \\
\hline \multirow{2}{*}{$\begin{array}{l}\text { Tdap vaccines (Tetanus Toxoid, Reduced } \\
\text { Diphtheria toxoid and acellular } \\
\text { pertussis - adolescent formulation) } \\
\text { a. Boostrix ® (GSK) } \\
\text { b. Adacel } ® \text { (Sanofi Pasteur) }\end{array}$} & July 8, 2011 & $\begin{array}{l}\text { FDA approved Boostrix (Tdap, GlaxoSmithKline) } \\
\text { to prevent tetanus, diphtheria, and pertussis } \\
\text { in older people. }\end{array}$ \\
\hline & June 10, 2005 & $\begin{array}{l}\text { FDA licensed a } 2 \text { nd Tdap vaccine (Adacel by sanofi } \\
\text { pasteur) for use in persons ages } 11-64 \text { years. }\end{array}$ \\
\hline $\begin{array}{l}\text { Varicella Vaccine } \\
\text { a. Varivax } ®(\text { Merck) }\end{array}$ & Mar 17, 1995 & $\begin{array}{l}\text { Varicella virus vaccine, live (Varivax by Merck) was } \\
\text { licensed for the active immunization of persons } 12 \\
\text { months of age and older. }\end{array}$ \\
\hline \multirow{4}{*}{$\begin{array}{l}\text { Combination Vaccines } \\
\text { a. Kinrix } ®(G S K) \\
\text { b. Pediarix }{ }^{\circledR}(\mathrm{GSK}) \\
\text { c. ProQuad } ®(\text { Merck }) \\
\text { d. Quadracel }{ }^{\circledR} \text { (Sanofi Pasteur) }\end{array}$} & June 24, 2008 & $\begin{array}{l}\text { FDA approved new DTaP-IPV vaccine (Kinrix) for } \\
\text { use in children ages } 4-6 \text { years. }\end{array}$ \\
\hline & Dec 13, 2002 & $\begin{array}{l}\text { A vaccine that combined the diphtheria, tetanus, } \\
\text { acellular pertussis, inactivated polio, and hepatitis } \\
\text { B antigens (Pediarix by GlaxoSmithKline) was licensed. }\end{array}$ \\
\hline & Sept 6, 2005 & $\begin{array}{l}\text { A vaccine that combined the measles, mumps, rubella, } \\
\text { and varicella antigens (Proquad by Merck) was } \\
\text { licensed. The vaccine was indicated for use in children } \\
12 \text { months to } 12 \text { years. }\end{array}$ \\
\hline & March 24, 2015 & $\begin{array}{l}\text { FDA approved Quadracel, a new combination DTaP+IPV } \\
\text { vaccine for use in children age } 4-6 \text { years. }\end{array}$ \\
\hline
\end{tabular}

response is created by toxoid vaccines resulting from detoxification of secretory toxin by heat or formalin treatments.

Examples of toxoid vaccines are including vaccines developed against diphtheria, tetanus, and pertussis toxins. For instance, DTaP Vaccine is a combined vaccine for protection of children against diphtheria and tetanus and pertussis diseases. A new version of this vaccine called Tdap is also developed for protection of adults against the noted diseases (Yih et al. 2009).

Totally, high safety and stability as well as transmission inability to non-immunized persons are the major properties of toxoid vaccines. However, one of the major drawbacks of vaccination with toxoids is the requisite of more than one dose of vaccine to provoke protective immunity, a phenomenon necessitating the presence of adjuvant with toxoid (Baxter 2007).

\section{Recombinant protein vaccines}

The production of recombinant proteins is one of the new approaches to create safe vaccines especially against nonculturable or difficult-to-culture viruses (Hudu et al. 2016) (Eisenstein 2011). The recombinant protein vaccines as the third-generation vaccines can induce both humoral (antibody) and cellular immune responses in the host (Fig. 1). In this type of vaccines, genes encoding protective antigens are recombinantly expressed (Baxter 2007) (Scott and Cheryl 2004).

In 1987, Hilleman $\mathrm{M}$ et al. developed Recombivax as the first recombinant vaccine against hepatitis B through cloning and recombinant expression of the hepatitis B surface antigen in Saccharomyces cerevisiae (Hilleman 1987). Until now, numerous recombinant vaccines have been approved against viral pathogens such Human papilloma virus (Slade et al. 2009), 
Fig. 1 Several generations of vaccines have been developed to control infectious diseases through inducing immune responses in the host

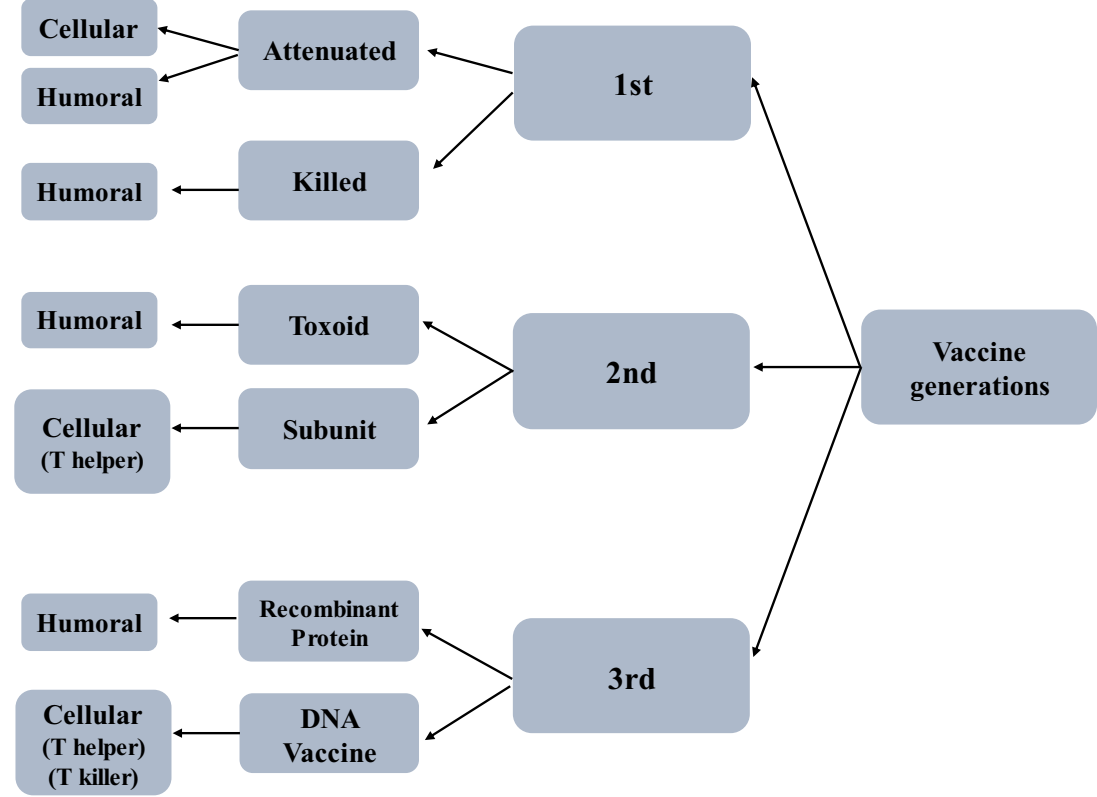

Influenza (Girard et al. 2013), and bacterial pathogens including Bacillus Calmette-Guerin (BCG) (Jacobs et al. 1990) and Meningococcal (Cooper et al. 2011).

Recently, a recombinant vaccine called shingrix has been developed against shingles disease caused by the varicella zoster virus with a high level protection (up to 90\%) against this disease (Raedler 2018). One of the main challenges in the development of recombinant vaccines is the selection of the suitable target antigens. At present, reverse vaccinology is one of the promising approaches to identify repertoire of antigens that are highly antigenic, with surface exposure, and conserved among multiple strains (Rappuoli et al. 2016) (Zeng et al. 2017).

\section{DNA vaccines}

In DNA vaccines, immune response is induced through plasmid DNA encoding interested antigen (Fig. 1). Owing to safety and simplicity, DNA vaccines have several advantages over conventional vaccines especially in compare to attenuated and killed vaccines. After transfection of plasmid DNA, target antigen is expressed inside cells and induces immune responses of the host (Hudu et al. 2016). Although DNA vaccines have several benefits including high stability, cost affectivity and the ability to induce both humoral and cellular immune responses, some limitations still exist regarding the use of these vaccines (Okuda et al. 2014). For instance, due to the low extent of antigens produced in the body, Th2-type immune responses is weakly induced in DNA vaccines (Shi et al. 2014). At present, researchers using techniques such as in vivo electroporation have improved the efficacy of these vaccines.
Until now, several DNA vaccines have been developed some of which are under clinical studies but none of them approved yet (Bar-Or et al. 2007) (Papadopoulou et al. 2012). For instance, Bar-Or et al. used DNA encoding myelin protein as vaccine for immunotherapy of multiple sclerosis (MS). The results indicated a notable reduction in levels of myelin-specific autoantibodies (Bar-Or et al. 2007) (Papadopoulou et al. 2012). In another study, a DNA plasmid encoding $A \beta 42$ protein was developed as DNA vaccine against Alzheimer disease (Lambracht-Washington and Rosenberg 2012). Recently, researchers have developed a DNA vaccine with ability to induce immune responses in immunized mice against Acinetobacter (A.) baumannii through importing Acinetobacter NlpA gene into pEGFP-C2 vector (Hashemzehi et al. 2018). Also, a DNA vaccine has developed against Vibrio (V.) anguillarum through construction of OmpK gene as immunogenic protein of $V$. anguillarum in pcDNA3.1 vector that can induce humoral and cellular immune responses in immunized fish with vector expressing OmpK gene (Xu et al. 2019).

Unlike, other vaccines such as recombinant protein vaccines and live attenuated virus which their generation is prolonged and costly, DNA vaccines are flexible and produced quickly. However, there are some limitations in the use of DNA vaccines such as inducing weak immune response, the probability of activation of oncogenes during genomic integration of DNA vaccines, as well as production of anti-DNA antibodies in the body (Harrison and Bianco 2000). Because of these limitations, no DNA vaccines have been FDA approved to combat infections. 


\section{Subunit vaccines}

Subunit vaccines are produced through purification of antigens directly from the pathogen. So that, based on the type of antigen (surface molecules, subcellular, and toxins) used in subunit vaccine, the type of immune responses in the host is different (Baxter 2007) (Scott and Cheryl 2004). Polysaccharide antigens induce T-independent immune response whereas protein antigens induce $\mathrm{T}$ cell-dependent responses. Conjugated vaccines are another type of subunit vaccines in which a protein carrier is used to deliver the polysaccharide antigen. In this type of vaccine, polysaccharide with poorly immunogenic property is conjugated to a protein carrier which is strongly immunogenic.

In the conjugated vaccines, both T-dependent and Tindependent immune responses are activated in the host. Totally, Diphtheria Toxoid D (Pace and Pollard 2007), CRM197 (Shinefield 2010), Protein D (Plosker 2014), or Outer Membrane Protein Complex (OMPC) (Lenoir et al. 1987) are the most common carriers used in conjugated vaccines. At present, several conjugated vaccines have been approved to control infections; for instance, PedvaxHIB is a conjugated vaccine in which capsular polysaccharide of Haemophilus influenzae type $\mathrm{b}$ has been conjugated to outer membrane protein of Neisseria (N.) meningitidis group B (Ahonkhai et al. 1990). Pneumococcal 13-valent conjugate vaccine with trade name Prevnar 13 is composed of diphtheria CRM197 protein as carrier and seven serotypes of Streptococcus (S.) pneumoniae (4, 18C, 6B, 19F, 9V, 14 and 23F).

Pentacel as a pentavalent vaccine conjugated to Tetanus toxoid is made for simultaneous protection against pertussis, tetanus, diphtheria, Haemophilus influenzae type b, and polio diseases (Sucher et al. 2011). Menveo conjugated vaccine composed of diphtheria CRM197 oligosaccharide and has been developed for immunization against four serogroups of N. meningitidis bacteria (A, C, Y, and W-135) causing invasive meningococcal disease (Deeks 2010). Recently, a Modified Vaccinia Ankara (MVA) expressing the ZIKV protein NS1 (ZIKV-NS1) has been developed with ability of inducing robust humoral and cellular responses in adult mice (Brault et al. 2017).

\section{Antibody therapy against infectious diseases}

Despite considered advantages of vaccines for prophylaxy of infectious diseases, there are some limitations regarding induction of immune responses, especially in immunosuppressed individuals such as diabetics, bone marrow suppressed and HIV patients. In this respect, antibody therapy can be an attractive approach for providing temporary protection against a microbial agent. Commonly, antibody therapy is faster than vaccines in emergency situations (Graham and
Ambrosino 2015). Until now, several antibodies have been approved to treat a number of diseases such as some types of cancer and autoimmune disorders (Eyvazi et al. 2018).

Previous studies for control of $A$. baumannii infections by immunization indicated that, use of immune serum as passive immunization and or A. baumannii bacteria as active immunization both have protective effect on mice suffering from pneumonia or lethal bacteremia infections (McConnell et al. 2011., McConnell and Jerónimo 2010) (Huang et al. 2014).

In the 1890 s, for the first time, antibodies were extracted from immunized animal's serum and introduced as therapeutic agents to bacterial infections. Emil von Behring first indicated that serum of rabbit immunized with tetanus toxin can control tetanus infection in the rabbits (Winau and Winau 2002) (Casadevall and Scharff 1994). Afterwards, Emil von Behring received Nobel Prize in 1901 due to development of serum therapy to diphtheria (Winau and Winau 2002). Until the early twentieth century, serum therapy was a successful treatment against most of viral infections such as influenza, measles (Janeway 1945), and polio (Hammon et al. 1954) and bacterial infections including Haemophilus influenza $\mathrm{B}$, meningococcus, and pneumococcus (Alexander et al. 1946) (Casadevall and Scharff 1994). However, when antibiotics as therapeutics agents of bacterial infections were discovered, the application of serum therapy was reduced. With development of hybridoma technology by Milstein and Köhler in 1975 regarding generation of murine monoclonal antibodies through immortalizing B cells known as hybridomas, a new era was began in the treatment of different diseases using monoclonal antibodies and passive immunization (Köhler and Milstein 1975).

Although hybridoma technology have made a notable contribution in the discovery of antibodies but animal-based approaches displayed some limitations especially for toxic and hapten targets. To eliminate these limitations, researchers have developed new non-animal-based strategies to develop monoclonal antibodies such as phage display libraries.

At present, two main strategies for developing mAbs are used including animal immunization and surface display methodologies such phage display technology (McCafferty et al. 1990) (Rahbarnia et al. 2017b).

Antibody phage display technology is an in vitro screening process independent from any immune system in which the antibody fragments are displayed in phages surface (Rahbarnia et al. 2017a). For instance, human scFv phage library with high diversity of gene repertoires provides a rich source of scFvs to almost any antigen (Rahbarnia et al. 2017b).

Until now, several mAbs have been approved to combat infectious disease. For instance, Raxibacumab (ABthrax $\left.{ }^{\circledR}\right)$ as the first antitoxin antibody is a human IgG1 produced by phage display technology against Bacillus (B.) anthracis protective antigen which has been approved in 2012 to prevent 
inhalation anthrax (Migone et al. 2009). Bezlotoxumab is another example of human monoclonal antibody approved in 2017 that has been developed to prevent Clostridium difficile infection through targeting toxin B (Navalkele and Chopra 2018). Finally, Obiltoxaximab (Anthim $®)$ is a Chimeric (mouse/human) IgG1/K antibody approved in 2016 which was produced as a preventive agent against $B$. anthracis. This antibody targets protective antigen (PA) component of B. anthracis toxin (Capela et al. 2017).

Currently, monoclonal antibodies are used for treatment of several diseases including cancer, Crohn's disease, rheumatoid arthritis, ulcerative colitis, and multiple sclerosis. However, antibody therapy of infectious diseases is limited due to the need for high doses of antibodies and cost of manufacturing (Patel et al. 2018). So that, studies regarding application of monoclonal antibodies have only been focused on bacteria that cause toxin-mediated infection (e.g., Anthrax, Clostridium (C.) difficile colitis), and viral diseases such Ebola, HIV, MERS, and SARS which had no available vaccines (Graham and Ambrosino 2015).

Therefore, the alternative therapeutic approaches such as vaccines and antimicrobials have priority over infection prevention and control.

Recently, researchers have developed a novel technology known as DNA-encoded monoclonal antibodies (DMAbs) to target Zaire Ebola virus that unlike the conversional antibodies provide a long-term protection against Ebola virus. It is now under preclinical trials (Patel et al. 2018).

\section{Antimicrobial peptides}

Antimicrobial peptides (AMPs) or host defense peptides (HDPs) are conserved molecules that act as one of the host defense mechanisms to combat infections (Yeaman and Yount 2003). AMPs exhibit in living organisms from prokaryotes to humans. At present, AMPs are considered as promising therapeutic candidates due to their key role in the regulation of arteriogenesis, inflammatory responses, angiogenesis, wound healing responses, and cell signaling pathways (Zaiou 2007) (Baba et al. 2015., Kim et al. 2015).

In 1939, Gramicidin as the first natural AMPs was identified from Bacillus brevis with antimicrobial activity against gram positive bacteria. Further studies confirmed its antimicrobial activity regarding guinea pig wound infections as alternative to antibiotics (Dubos 1939). After that, several host defense peptides (HDPs) were identified in living organisms such Hyalophora cecropia (cecropins), Xenopus laevis (magainins) (Steiner et al. 1981) (Zasloff et al. 1988). Generally, the unique structural properties of AMPs distinct them from other molecules; for instance, the net positive charge of AMPs facilitates electrostatic interactions with anionic lipopolysaccharides or lipoteichoicacids of microbial membranes (Jenssen et al. 2006;
Yeaman and Yount 2003). Also, due to hydrophobicity characteristic, AMPs can penetrate into the host cells to lyse membrane (Aoki and Ueda 2013).

It should be also noted that the antibacterial potency of AMPs is strongly dependent on their secondary structure; for instance, $\alpha$-helical content in linear AMPs affects their antimicrobial activity (Jenssen et al. 2006).

Until now, more than 1500 AMPs have been isolated from several organisms including fungi, plants, bacteria, and animals (Naafs 2018). But only a limited number AMPs are approved for clinical use due to proteolytic degradation and low stability in the body.

Cyclic AMPs were the first AMPs offered for clinical use including Polymyxins, Gramicidin, Tyrothricin (tyrocidin is the main component), Bacitracin, and Daptomycin (Molchanova et al. 2017). In this respect, Polymyxins are considered as last line therapy for multidrug-resistant infections caused by Gram-negative bacteria which first isolated from Paenibacillus polymyxa strains. However neuro- and nephrotoxicity problems have limited Polymyxins application (Lenhard et al. 2019). At present, researchers have generated several analogs of Polymyxins with low toxicity such as CB182,804, Pfzer 5X, Monash FADDI, Queensland, Northern antibiotics (Rabanal and Cajal 2017) but neither of them have been approved (Lenhard et al. 2019).

For instance, Daptomycin (Cubicin $®)$ was approved in 2003 for the treatment of skin and bloodstream infections caused by susceptible and methicillin-resistant strains of Staphylococcus aureus (Afacan et al. 2012). After that, Surotomycin (CB-315, CB-183315, and MK4261) as one of daptomycin analogs was developed to treat $C$. difficile-associated diarrhea, but recently, it was failed due to lack of superiority over standard of treatment (Boix et al. 2017) (Petrosillo et al. 2018). Murepavadin (POL 7080) as cyclic synthetic peptide (14aa) is known as an attractive drug to treat ventilator-associated pneumonia (VAP) and hospitalacquired pneumonia (HAP) caused by Pseudomonas. It functions through interaction with lipopolysaccharide transport protein D (LptD) and blocks export mechanism of LPS in the outer membrane and kill the bacterium. The phase 2 clinical trials of this peptide has been completed regarding noncystic fibrosis bronchiectasis (Butler et al. 2017). Recently, the phase III trials of murepavadin to treat nosocomial pneumonia have been stopped due to occurrence of higher than estimated of acute kidney injury in patients treated with murepavadin) https://www.polyphor.com/news/ corporate-news-details/?newsid=1775911).

Besides cyclic analogs, today several linear AMPs have been identified that are effective towards wide range of gram-positive and gram-negative bacteria; for instance, antimicrobial characterization of pexiganan is confirmed towards Methicillin-resistant Staphylococcus (S.) aureus, extended spectrum beta-lactamases (ESBL) producing bacteria, 
vancomycin-resistant Enterococcus (VRE) (Afacan et al. 2012) (Rabanal and Cajal 2016). In addition to the noted cases, several AMPs such Omiganan (CLS001 or MBI-226) (Sierra et al. 2017), SGX942 (dusquetide) (Kudrimoti et al. 2017), LTX-109 (Lytixar) (Sierra et al. 2017) are now under clinical studies.

Recently, a cationic peptide called as PEP-NJSM has been identified to treat $S$. epidermidis biofilm formation-related infections (Mnif et al. 2019).

Although notable success has been achieved in identification of novel AMPs, but due to the proteolytic degradation and toxicity of AMPs, rarely approved by FDA. Hence, one of the major challenges of the scientists is related to increase of stability, safety, and efficiency of AMPs.

\section{Genome editing technologies to fight infectious diseases}

Newly, genome engineering using programmable nucleases has been developed to treat various types of disorders (Safari et al. 2018).

So far, four types of engineered nucleases have been applied for targeted genome modification including transcription activator-like effector nucleases (TALENs), and zinc-finger nucleases (ZFNs), homing endonucleases (HEs), and clustered regularly interspaced short palindromic repeat (CRISPR-Cas9).

In the beginning, these nucleases identify target DNA sequence and break the double stranded DNA then the created gap is repaired by two distinct mechanisms comprising nonhomologous end joining pathways (NHEJ) and homologous recombination (HR) (Rouet et al. 1994). HR strategy is only suitable to insert a high copy number from a homologous sequence while NHEJ creates insertions or deletions (known indels) as an error-prone mechanism (Isken and Maquat 2007) (Kucherlapati et al. 1984).

Researchers to struggle infectious diseases through genome editing target crucial genes involved in virulence, replication, and activation of pathogen through the error-prone NHEJ mechanism. However, the utilization of the NHEJ against viruses is only limited to viruses carrying DNA, such as human immunodeficiency virus (HIV), since these programmable nucleases can cut only genomic DNA. Recently, the modified CRISPR-Cas9 system has been developed to produce gRNAs complementary to the genome of hepatitis $\mathrm{C}$ virus (HCV), to target RNA-based viruses (Price et al. 2015).

In a recent study, the replication of HIV virus was limited considerably through a combinatorial CRISPR/Cas9 system to target several regions of the HIV genome by two strong gRNAs (Lebbink et al. 2017).
The utilization of genome editing strategy in order to target virulence factors and bacterial antibiotic resistance genes back to 2004 year when Citorik et al., employed viral transduction method to transfer molecular constructs into the bacterial cells (Citorik et al. 2014). In this method, M13-phagemid vector carrying CRISPR-Cas9-based RNA-guided nucleases was used for targeting the blaSHV-18 or blaNDM-1 genes, responsible for extended spectrum and pan-resistance to $\beta$ lactam antibiotics, respectively (Citorik et al. 2014).

In another study, researchers examined the specificity of the CRISPR-Cas system for introduction of a singlenucleotide mutation in the gyrase gene (gyrAD87G) which is responsible for resistance to quinolones. Results were confirming the specificity of CRISPR-Cas system so that only Escherichia coli cells harboring the gyrAD87G mutation were killed by a phagemid vector but not $E$. coli strains carrying the wild-type gyrA gene (Citorik et al. 2014).

In a study done by Bikard et al. in 2014, CRISPR-Cas system was used for targeting the methicillin resistance gene, mecA, in $S$. aureus that led to the notable reduction of methicillin resistance. Also, studies indicated that, this antimicrobial system leads to immunization of nonpathogenic S. aureus strains towards the transfer of antibiotic-resistant plasmids (Bikard et al. 2014). After that, in vivo studies on mouse infected to $S$. aureus was confirming more effect of CRISPR-Cas9 phagemids to treat skin colonization than standard therapy with mupirocin (Bikard et al. 2014).

Recently, in one study on Enterococcus (E.) faecalis, CRISPR-Cas genome defense system was used to block the acquisition of antibiotic resistance by horizontal transfer system in E. faecalis (Rodrigues et al. 2017).

Although notable advances have been achieved regarding employment of genome editing strategy against infectious diseases, there are still some limitations for the use of this tool in clinical settings, such as the possibility of mutants escape or off-target mutations in the genome, so recent efforts of researchers are in order to increase specificity and sensitivity of genome editing and predicting off-target effects. However, the prediction of cleavage rate and nuclease target availability in living cells is difficult due to the complexity of chromatin structure and cell nucleus.

\section{RNA interference-based therapeutics to combat infections}

RNA interference (RNAi) technology is known as one of the promising therapeutic strategies regarding autoimmune disorders, cancer, and infectious diseases (Dyawanapelly et al. 2014; Zarredar et al. 2019). Generally, RNAi technology relies on the use of specific nucleic acids such as siRNAs and miRNA for knockdown or knockout expression of the genes involved in disease. 
The modern era in the treatment of intracellular infections by RNAi technology was begun when McCaffrey et al. employed specific siRNAs and shRNAs to target key genes of hepatitis C virus (McCaffrey et al. 2002). Afterwards, Bitko et al. achieved promising results regarding Para influenza virus control through specific siRNA design (Bitko et al. 2005).

Until now, several types of nucleic acids including DNAs, siRNAs, miRNA, and shRNA have been used effectively to harness lethal intracellular infections (Blagbrough and Zara 2009). MicroRNAs (miRNAs) are small non coding RNAs ( $\sim 22 \mathrm{nt})$ that bind to complementary sequences in the $3^{\prime}$-untranslated region of messenger RNA and control transcription and translation processes (Bartel 2009). In comparison with siRNA, application of miRNA as therapeutic agents is limited due to low specificity and their unpredictable mechanism so that only two miRNAs have been developed as therapeutic candidate (Lam et al. 2015). However, miRNAs are notable regarding mutagenic diseases such as cancer (Lam et al. 2015) (Fig. 2).

SiRNAs as main regulators of the post-transcriptional gene silencing pathways are more efficient than other types of nucleic acids (Pushparaj et al. 2008) (Khatri et al. 2012). The inhibitory effect of siRNAs was documented when Bitko and Barik harnessed growth of respiratory syncytial virus (RSV) through a synthetic siRNA blocking mRNAs coding protein $\mathrm{F}$ and polymerase of viral (Bitko et al. 2005).

During the past decade, satisfactory outcomes have been achieved regarding RNAi-based therapy of intracellular infections such malaria, HIV/AIDS, influenza, tuberculosis, leishmaniasis, RSV, hepatitis, and other infections (Dyawanapelly et al. 2014).

For instance, leishmaniasis is a parasitic disease that is presented in three forms cutaneous, mucocutaneous, and visceral leishmaniasis (VL). At present, chemotherapy is the most common therapeutic strategy against leishmania. However, emergence of drug-resistant parasites has limited conventional therapeutic approaches (Farajnia et al. 2011) (Rahbarnia et al. 2012). In this respect, researchers have examined the application of RNAi technology to harness leishmaniasis disease. For this, Robinson et al. targeted $\alpha$-tubulin locus by siRNA to restrain growth of leishmania parasite but the results were not promising (Robinson and Beverley 2003). In study undertaken by Dey et al., a specific siRNA was used to silence $\mathrm{C}-\mathrm{C}$ chemokine receptor 5 (CCR5) in leishmania through which the parasite titer was considered declined in murine visceral leishmaniasis treated by CCR5 siRNA in the primary stage of infection (Bhattacharyya et al. 2008).

Nevertheless, researches in the field of gene therapy of bacterial infections are more promising. For instance, researchers employed a siRNA (21 bp) to target coagulase activity in methicillin-resistant $S$. aureus (MRSA) strains and revealed inhibitory effect of the siRNA in MRSA coagulation under in vitro conditions. Also, inhibitory effect of the synthetized siRNA was confirmed by remarkable reduction of the bacterial titer in a murine model infected by hematogenous pulmonary infection (Yanagihara et al. 2005).

One of the recent reports regarding siRNAs application is related to Nile virus (WNV) control (Beloor et al. 2018). At

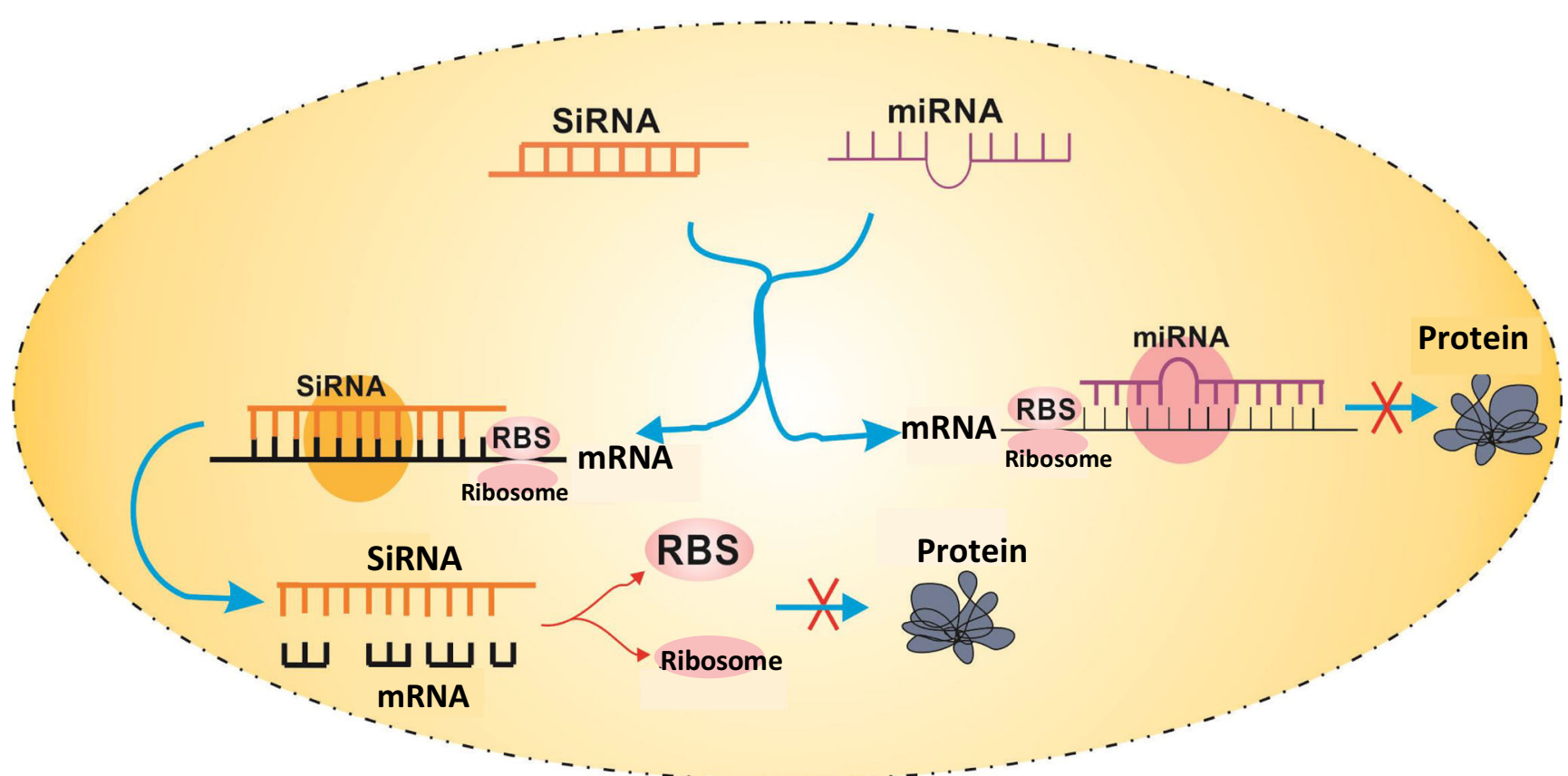

Fig. 2 The miRNAs and siRNAs can bind to complementary sequences in mRNA and regulate the expression of gene through translational repression, degradation of mRNA. The miRNAs target mRNAs through partial complementarity while siRNA bind to mRNA as fully complementary base pairing 
present, there is no vaccine against this virus. During the study done by J. Beloor, a synthetic RNA called siFvEJW was designed to limit WNV through targeting a conserved sequence in $\mathrm{E}$ protein of the WNV. The results of in vivo studies indicated the inhibitory effect of the siRNA in mice at late stages of neuroinvasive disease (Beloor et al. 2018).

Although siRNAs have been known as promising therapeutic tools, but their application has been limited due to the low stability, the possibility of immunogenicity, degradation and off-target effects (Ryther et al. 2005) (Whitehead et al. 2009).

One of the main challenges facing researchers is the choice of suitable cellular carriages such viral and non-viral vectors for the effective delivery of siRNAs (Thomas et al. 2007) (Islam et al. 2014). The most common viral vectors used are including retrovirus vectors, lentivirus, adeno-associated virus, oncoretrovirus, adenovirus, and herpes simplex virus-1based vectors (Islam et al. 2014, Lambracht-Washington and Rosenberg 2012., Oh and Park 2009). Totally, the viral vectors have higher efficiency but immunogenicity, carcinogenicity, and inducing inflammatory responses and possibility of integration into the host genome limit their therapeutic applications. In contrast, researchers have developed non-viral vectors with higher safety, efficiency, and ability to systemic and/ or local delivery of nucleic acid (Semple et al. 2010) (Wang et al. 2010).

Recently, RNA nanomedicine technology as one of nonviral nanovector systems has been developed for effective delivery of small RNA-based therapeutics (Riley and Vermerris 2017).

The recent efforts have been focused on increase of the stability of small RNAs versus nucleases in order to improve of small RNAs effectiveness as attractive therapeutic tools.

\section{Phage therapy}

The history of phage therapy for control of infections go back to when antibiotics still had not been discovered. Commonly, phages can control infections through lysis of infected bacteria (Lin et al. 2017). Since phages target only specific bacterial species and have no effect on the normal bacterial flora, so the possibility of secondary infections in phage therapy is lower than antibiotic therapy. Despite, many advantages of phage therapy such high specificity, low toxicity and selfamplification and anti-biofilm activity, there is no still FDA approved phage therapy as alternative to antibiotics (Donlan 2009) (Bourdin et al. 2014), because of phages that are usually identified and eliminated by the host immune system through generation of specific antibodies. On the other hand, intracellular infections maybe inaccessible for phage particles (Henein 2013). Nevertheless, the emergence of antibiotic-resistant infections has been led to redevelopment of phage therapy as alternative to treat infections. One of the notable progresses in phage therapy is related to identification of the genes encoding lytic enzymes of phage that are expressed during lytic cycle by the bacterial host. The lytic proteins hydrolyze the cell wall of the host to excrete viral progeny. In this respect, two main classes of lytic proteins have been isolated comprising a peptidoglycan protein called lysine and a transmembrane protein known as holin which lysine protein plays the main role in the lysis of bacterial cell, so it is more notable as an antimicrobial candidate (Lin et al. 2017). In a study performed on diabetic patients, phage therapy significantly reduced the foot ulcer infections caused by MDR S. aureus (Fish et al. 2016).

Newly, researchers improved the efficiency of phage therapy to target drug-resistant bacteria through engineering phages and using of the lytic enzymes of phages (Lin et al. 2017). Until now, several lytic proteins such ABgp46, PlyF307, Cpl-1, PlyCD, and PlySs2 have been purified and their antibacterial properties confirmed against various drug-resistant bacteria such as MDR A. baumannii, Pseudomonas (P.) aeruginosa, and Salmonella (S.) typhimurium, S. pneumoniae, and MRSAs (Oliveira et al. 2016),(Schmelcher et al. 2015). For instance, in one study, a phage cocktail was designed to treat wound infections caused by $A$. baumannii in which four $A$. baumannii lysing phages were combined to one phage inhibiting bacterial growth to target both capsulated and uncapsulated bacteria. The inhibitory effect of the cocktail phage was confirmed on murine model (Regeimbal et al. 2016).

Although there are many unknown factors regarding phage therapy and phage-host interactions, however, advances in the field of phage therapy as an alternative to antibiotics are significant.

\section{Conclusion and perspectives}

Despite notable advances regarding production of vaccines and new antibiotics, drug-resistant infections are still a serious threat to public health. At present, several promising therapeutic strategies have been developed against infectious diseases, each of them has own advantages and disadvantages.

For instance, today, vaccination is effective for prophylaxis of many infectious diseases but there is no effective vaccine to HIVs, TB, and several other infections. In this respect, RNAi technology is a promising strategy to struggle intracellular infections, including HIV/AIDS, hepatitis, RSV, influenza, HSV, malaria, and tuberculosis but still there are challenges regarding employment of suitable carriers such viral and nonviral vectors for the effective delivery of RNAs. In addition to RNAi technology, CRISPR has newly been implemented to target virulence factors of infectious bacteria. Despite the notable advances regarding the feasibility of harnessing CRISPR 
strategy for tackling infections, the improvement of CRISPR technology through production of nucleases with more cleavage efficiency and specificity is still needed. On the other hand, development of appropriate delivery systems with higher safety could improve treatment of resistant infections by CRISPR technology (Trevisan et al. 2017).

In addition to the mentioned therapeutic strategies, more than 2,000 natural and synthetic AMPs have been developed as alternative to antibiotics (Wang et al. 2016) but only a few AMPs has reached to the clinical use (Li et al. 2017). The unknown molecular mechanisms of AMPs in the host and necessity of rational design of AMPs are two main barriers in the development of more efficient AMPs (Andersson et al. 2016).

To accomplish the potential role of the abovementioned strategies against antibiotic resistance threat, efforts need to be accelerated and investments expanded at all stages of research, preclinical, and clinical developments.

Funding information This study was supported by Infectious and Tropical Diseases Research Center, Tabriz University of Medical Sciences, Tabriz, Iran.

\section{Compliance with ethical standards}

Conflict of interest The authors declare that they have no conflict of interest.

Ethical statement This article does not contain any studies with human participants or animals performed by any of the authors.

\section{References}

Afacan NJ, Yeung AT, Pena OM, Hancock RE (2012) Therapeutic potential of host defense peptides in antibiotic-resistant infections. Curr Pharm Des 18(6):807-819

Ahonkhai VI, Lukacs LJ, Jonas LC, Matthews H, Vella PP, Ellis RW, Staub JM, Dolan KT, Rusk CM, Calandra GB (1990) Haemophilus influenzae type $\mathrm{b}$ conjugate vaccine (meningococcal protein conjugate)(PedvaxHIBTM): clinical evaluation. Pediatr. 85(4): 676-681

Alexander HE, Leidy G, Geof R, Rich D (1946) Hemophilus influenzae meningitis treated with streptomycin. JAMA. 132(8):434-440

Andersson DI, Hughes D, Kubicek-Sutherland JZ (2016) Mechanisms and consequences of bacterial resistance to antimicrobial peptides. Drug Resist Updat 26:43-57

Aoki W, Ueda M (2013) Characterization of antimicrobial peptides toward the development of novel antibiotics. Pharm. 6(8):1055-1081

Baba MS, Zin NM, Hassan ZAA, Latip J, Pethick F, Hunter IS, EdradaEbel R, Herron PR (2015) In vivo antimalarial activity of the endophytic actinobacteria, Streptomyces SUK 10. J Microbiol 53(12): 847-855

Bar-Or A, Vollmer T, Antel J, Arnold DL, Bodner CA, Campagnolo D, Gianettoni J, Jalili F, Kachuck N, Lapierre Y (2007) Induction of antigen-specific tolerance in multiple sclerosis after immunization with DNA encoding myelin basic protein in a randomized, placebocontrolled phase 1/2 trial. Arch Neurol 64(10):1407-1415
Bartel DP (2009) MicroRNAs: target recognition and regulatory functions. Cell 136(2):215-233

Baxter D (2007) Active and passive immunity, vaccine types, excipients and licensing. Occup Med 57(8):552-556

Beloor J, Maes N, Ullah I, Uchil P, Jackson A, Fikrig E, Lee SK, Kumar P (2018) Small interfering RNA-mediated control of virus replication in the CNS is therapeutic and enables natural immunity to West Nile virus. Cell Host Microbe 23(4):549-556

Bhattacharyya S, Dey R, Majumder N, Bhattacharjee S, Majumdar S (2008) A novel approach to regulate experimental visceral leishmaniasis in murine macrophages using CCR5 siRNA. Scand J Immunol Suppl 67(4):345-353

Bikard D, Euler CW, Jiang W, Nussenzweig PM, Goldberg GW, Duportet X, Fischetti VA, Marraffini LA (2014) Exploiting CRISPR-Cas nucleases to produce sequence-specific antimicrobials. Nat Biotechnol 32(11): 1146

Bitko V, Musiyenko A, Shulyayeva O, Barik S (2005) Inhibition of respiratory viruses by nasally administered siRNA. Nat Med 11(1):50

Blagbrough IS, Zara C (2009) Animal models for target diseases in gene therapy using DNA and siRNA delivery strategies. Pharm Res 26(1):1

Boix V, Fedorak RN, Mullane KM, Pesant Y, Stoutenburgh U, Jin M, Adedoyin A, Chesnel L, Guris D, Larson KB, Murata Y (2017) Primary outcomes from a phase 3 , randomized, double-blind, active-controlled trial of surotomycin in subjects with Clostridium difficile infection. Open Forum Infect Dis 4(1)

Bourdin G, Navarro A, Sarker SA, Pittet A, Qadri F, Sultana S, Cravioto A, Talukder KA, Reuteler G, Brüssow H (2014) Coverage of diarrhoea associated Escherichia coli isolates from different origins with two types of phage cocktails. Microb Biotechnol 7(2):165-176

Brault AC, Domi A, McDonald EM, Talmi-Frank D, McCurley N, Basu R, Robinson HL, Hellerstein M, Duggal NK, Bowen RA (2017) A Zika vaccine targeting NS1 protein protects immunocompetent adult mice in a lethal challenge model. Sci Rep 7(1):14769

Butler MS, Blaskovich MA, Cooper MA (2017) Antibiotics in the clinical pipeline at the end of 2015. J Antibiot 70(1):3

Capela EV, Aires-Barros MR, Freire MG, Azevedo AM (2017) Monoclonal antibodies-addressing the challenges on the manufacturing processing of an advanced class of therapeutic agents. Front Clini Drug Res Anti Infect 4(4):142

Casadevall A, Scharff MD (1994) Serum therapy revisited: animal models of infection and development of passive antibody therapy. J Antimicrob Agents Chem 38(8):1695

Cassini A, Högberg LD, Plachouras D, Quattrocchi A, Hoxha A, Simonsen GS, Colomb-Cotinat M, Kretzschmar ME, Devleesschauwer B, Cecchini M, Ouakrim DA (2019) Attributable deaths and disabilityadjusted life-years caused by infections with antibiotic-resistant bacteria in the EU and the European Economic Area in 2015: a population-level modelling analysis. Lancet Infect Dis 19(1)56-66

Citorik RJ, Mimee M, Lu TK (2014) Sequence-specific antimicrobials using efficiently delivered RNA-guided nucleases. Nat Biotechnol 32(11): 1141

Clem AS (2011) Fundamentals of vaccine immunology. J Glob Infect Dis $3(1): 73$

Cooper B, DeTora L, Stoddard J (2011) Menveo®: a novel quadrivalent meningococcal CRM197 conjugate vaccine against serogroups A, C, W-135 and Y. Expert Rev Vaccines 10(1):21-33

Davies J, Davies D (2010) Origins and evolution of antibiotic resistance. Microbiol Mol Biol Rev 74(3):417-433

Deeks ED (2010) Meningococcal quadrivalent (serogroups A, C, W135, and $\mathrm{Y}$ ) conjugate vaccine (Menveo). BioDrugs 24(5):287-297

Donlan RM (2009) Preventing biofilms of clinically relevant organisms using bacteriophage. Trends Microbiol 17(2):66-72

Dubos RJ (1939) Studies on a bactericidal agent extracted from a soil bacillus: I. Preparation of the agent. Its activity in vitro. J Exp Med 70(1):1 
Dyawanapelly S, Ghodke SB, Vishwanathan R, Dandekar P, Jain R (2014) RNA interference-based therapeutics: molecular platforms for infectious diseases. J Biomed Nanotechnol 10(9):1998-2037

Eisenstein M (2011) A moving target. Nature. 474:S16-S17

El Chakhtoura NG, Saade E, Iovleva A, Yasmin M, Wilson B, Perez F, Bonomo RA (2018) Therapies for multidrug resistant and extensively drug-resistant non-fermenting gram-negative bacteria causing nosocomial infections: a perilous journey toward molecularly targeted therapy. Expert Rev Anti-Infect Ther 16(2):89-110

Eyvazi S, Farajnia S, Dastmalchi S, Kanipour F, Zarredar H, Bandehpour M (2018) Antibody based EpCAM targeted therapy of cancer, review and update. Curr Cancer Drug Targets 18(9):857-868

Farajnia S, Rahbarnia L, Alimohammadian MH, Abdoli OS, Beh-pajooh A, Saeedi N, Montazer SS (2011) Molecular cloning and characterization of P4 nuclease from Leishmania infantum. Enzyme Res 2011:1-6

Fish R, Kutter E, Wheat G, Blasdel B, Kutateladze M, Kuhl S (2016) Bacteriophage treatment of intransigent diabetic toe ulcers: a case series. J Wound Care 25(Sup7):S27-S33

Girard MP, Tam JS, Pervikov Y, Katz JM (2013) Report on the first WHO integrated meeting on development and clinical trials of influenza vaccines that induce broadly protective and long-lasting immune responses: Hong Kong SAR, China, 24-26 January 2013. Vaccine. 31(37):3766-3771

Graham BS, Ambrosino DM (2015) History of passive antibody administration for prevention and treatment of infectious diseases. Curr Opin HIV AIDS 10(3):129

Greenwood B (2014) The contribution of vaccination to global health: past, present and future. Phil Trans R Soc B 369(1645):20130433

Hammon WM, Coriell LL, Ludwig EH, McAllister RM, Greene AE, Sather GE, Wehrle PF (1954) Evaluation of Red Cross gamma globulin as a prophylactic agent for poliomyelitis: 5 . Reanalysis of results based on laboratory-confirmed cases. J JAMA 156(1):21-27

Harrison RA, Bianco AE (2000) DNA immunization with Onchocerca volvulus genes, Ov-tmy-1 and OvB20: serological and parasitological outcomes following intramuscular or GeneGun delivery in a mouse model of onchocerciasis. Parasite Immunol 22(5):249-257

Hashemzehi R, Doosti A, Kargar M, Jaafarinia M (2018) Cloning and expression of nlpA gene as DNA vaccine candidate against Acinetobacter baumannii. Mol Biol Rep:1-7

Henein A (2013) What are the limitations on the wider therapeutic use of phage? Bacteriophage 3(2):e24872

Hilleman MR (1987) Yeast recombinant hepatitis $B$ vaccine. Infection 15(1):3-7

Huang W, Yao Y, Long Q, Yang X, Sun W, Liu C, Jin X, Chu X, Chen B, Ma Y (2014) Immunization against multidrug-resistant Acinetobacter baumannii effectively protects mice in both pneumonia and sepsis models. PloS one 9(6):e100727

Hudu SA, Shinkafi SH, Shua U (2016) An overview of recombinant vaccine technology, adjuvants and vaccine delivery methods. Int $\mathrm{J}$ Pharm Pharm Sci 8:19-24

Infectious Diseases Society of America (IDSA) (2011) Combating antimicrobial resistance: policy recommendations to save lives. Clin Infect Dis 52(suppl_5):S397-S428

Isken O, Maquat LE (2007) Quality control of eukaryotic mRNA: safeguarding cells from abnormal mRNA function. Genes Dev 21(15):1833-3856

Islam MA, Firdous J, Choi YJ, Yun CH, Cho CS (2014) Regulation of endocytosis by non-viral vectors for efficient gene activity. J biomed Nanotechnol 10(1):67-80

Jacobs WR, Snapper SB, Lugosi L, Bloom BR (1990) "Development of BCG as a recombinant vaccine vehicle," in T-cell paradigms in parasitic and bacterial infections. Springer 153-160

Janeway CA (1945) Use of concentrated human serum $\beta$-globulin in the prevention and attenuation of measles. Bull N Y Acad Med 21(4):202
Jenssen H, Hamill P, Hancock RE (2006) Peptide antimicrobial agents. Clin Microbiol Rep 19(3):491-511

Kallerup RS, Foged C (2015) Classification of vaccines. In: Subunit vaccine delivery. Springer, Berlin, pp 15-29

Khatri NI, Rathi MN, Baradia DP, Trehan S, Misra A (2012) In vivo delivery aspects of miRNA, shRNA and siRNA. Crit Rev Ther Drug Carrier Syst 29(6):487-527

Kim H, Kim HR, Kim NR, Jeong BJ, Lee JS, Jang S, Chung DK (2015) Oral administration of Lactobacillus plantarum lysates attenuates the development of atopic dermatitis lesions in mouse models. J Microbiol 53(1):47-52

Köhler G, Milstein C (1975) Continuous cultures of fused cells secreting antibody of predefined specificity. Nature 256(5517):495

Kucherlapati RS, Eves EM, Song KY, Morse BS, Smithies O (1984) Homologous recombination between plasmids in mammalian cells can be enhanced by treatment of input DNA. Proc Natl Acad Sci 81(10):3153-3157

Kudrimoti M, Curtis A, Azawi S, Worden F, Katz S, Adkins D, Bonomi M, Scott Z, Elder J, Sonis ST (2017) Dusquetide: reduction in oral mucositis associated with enduring ancillary benefits in tumor resolution and decreased mortality in head and neck cancer patients. Biotechnol Rep 15:24-26

Kumar M (2016) Multidrug-resistant Staphylococcus aureus, India, 2013-2015. Emerg Infect Dis 22(9):1666

Lam JK, Chow MY, Zhang Y, Leung SW (2015) siRNA versus miRNA as therapeutics for gene silencing. Mol Ther Nucleic Acids 4

Lambracht-Washington D, Rosenberg RN (2012) Active DNA Aâ42 vaccination as immunotherapy for Alzheimer disease. Transl Neurosci 3(4):307-313

Lebbink RJ, De Jong DC, Wolters F, Kruse EM, Van Ham PM, Wiertz EJ, Nijhuis M (2017) A combinational CRISPR/Cas9 gene-editing approach can halt HIV replication and prevent viral escape. Sci Rep 7: 41968

Lenhard JR, Bulman ZP, Tsuji BT, Kaye KS (2019) Shifting gears: the future of polymyxin antibiotics. Antibiotics 8(2):42

Lenoir AA, Granoff PD, Granoff DM (1987) Immunogenicity of Haemophilus influenzae type $\mathrm{b}$ polysaccharide-Neisseria meningitidis outer membrane protein conjugate vaccine in 2-to 6month-old infants. Pediatr. 80(2):283-287

Lewis K (2013) Platforms for antibiotic discovery. Nat Rev Drug Discov 12(5):371

Li J, Koh JJ, Liu S, Lakshminarayanan R, Verma CS, Beuerman RW (2017) Membrane active antimicrobial peptides: translating mechanistic insights to design. Front Neurosci 11:73

Lin DM, Koskella B, Lin HC (2017) Phage therapy: an alternative to antibiotics in the age of multi-drug resistance. World J Gastrointest Pharmacol Ther 8(3): 162

Mak TW, Saunders ME (2005) The immune response: basic and clinical principles. Academic Press, Cambridge

McCafferty J, Griffiths AD, Winter G, Chiswell DJ (1990) Phage antibodies: filamentous phage displaying antibody variable domains. Nature 348(6301):552

McCaffrey AP, Meuse L, Pham TT, Conklin DS, Hannon GJ, Kay MA (2002) Gene expression: RNA interference in adult mice. Nature 418(6893):38

McConnell MJ, Jerónimo P (2010) Active and passive immunization against Acinetobacter baumannii using an inactivated whole cell vaccine. Vaccine. 29(1):1-5

McConnell MJ, Rumbo C, Bou G, Pachón J (2011) Outer membrane vesicles as an acellular vaccine against Acinetobacter baumannii. Vaccine. 29(34):5705-5710

Migone TS, Subramanian GM, Zhong J, Healey LM, Corey A, Devalaraja M, Lo L, Ullrich S, Zimmerman J, Chen A (2009) Raxibacumab for the treatment of inhalational anthrax. New Eng $j$ med 361(2):135-144 
Mnif S, Jardak M, Graiet I, Abid S, Driss D, Kharrat N (2019) The novel cationic cell-penetrating peptide PEP-NJSM is highly active against Staphylococcus epidermidis biofilm. Int J Biol Macromol 125:262-269

Molchanova N, Hansen PR, Franzyk H (2017) Advances in development of antimicrobial peptidomimetics as potential drugs. Molecules 22(9): 1430

Naafs MA (2018) The antimicrobial peptides: ready for clinical trials? Biomed J Sci Tech Res:1-4

Navalkele BD, Chopra T (2018) Bezlotoxumab: an emerging monoclonal antibody therapy for prevention of recurrent Clostridium difficile infection. Biologics. 12:11

Oh YK, Park TG (2009) siRNA delivery systems for cancer treatment. Adv Drug Deliv Rev 61(10):850-862

Okuda K, Wada Y, Shimada M (2014) Recent developments in preclinical DNA vaccination. Vaccines. 2(1):89-106

Oliveira H, Vilas BD, Sp M, Kluskens LD, Lavigne R, Sillankorva S, Secundo F, Azeredo J (2016) Structural and enzymatic characterization of ABgp46, a novel phage endolysin with broad anti-gramnegative bacterial activity. Front Microbiol 7:208

Pace D.,Pollard AJ., 2007. Meningococcal A, C, Y and W-135 polysaccharide-protein conjugate vaccines. Arch Dis Child . 92, (10) 909 915

Papadopoulou A, von Felten S, Traud S, Rahman A, Quan J, King R, Garren H, Steinman L, Cutter G, Kappos L (2012) Evolution of MS lesions to black holes under DNA vaccine treatment. J Neurol 259(7):1375-1382

Patel A, Park DH, Davis CW, Smith TR, Leung A, Tierney K, Bryan A, Davidson E, Yu X, Racine T (2018) In vivo delivery of synthetic human DNA-encoded monoclonal antibodies protect against Ebola virus infection in a mouse model. Cell Rep 25(7):1982-1993

Pehrsson EC, Tsukayama P, Patel S, Mejía-Bautista M, Sosa-Soto G, Navarrete KM, Calderon M, Cabrera L, Hoyos-Arango W, Bertoli MT (2016) Interconnected microbiomes and resistomes in lowincome human habitats. Nature 533(7602):212

Petrosillo N, Granata G, Cataldo MA (2018) Novel antimicrobials for the treatment of Clostridium difficile infection. Front Med 5:96

Plosker GL (2014) 10-valent pneumococcal non-typeable haemophilus influenzae protein D-conjugate vaccine: a review in infants and children. Paediatr Drugs 16(5):425-444

Pöri, Pinja (2018) Development of Vaccines. theseus.fi

Price AA, Sampson TR, Ratner HK, Grakoui A, Weiss DS (2015) Cas9mediated targeting of viral RNA in eukaryotic cells. Proc Natl Acad Sci 112(19):6164-6169

Pushparaj PN, Aarthi JJ, Manikandan J, Kumar SD (2008) siRNA, miRNA, and shRNA: in vivo applications. J Dent Res 87(11): 992-1003

Rabanal F, Cajal Y (2016) Therapeutic potential of antimicrobial peptides. In: New weapons to control bacterial growth. Springer, Berlin, pp 433-451

Rabanal F, Cajal Y (2017) Recent advances and perspectives in the design and development of polymyxins. Nat Prod Rep 34(7):886-908

Raedler LA (2018) Shingrix (zoster vaccine recombinant) a new vaccine approved for herpes zoster prevention in older adults. Am Health Drug Benefits 11

Rahbarnia L, Farajnia S, Naghili B (2012) Application of DsbA signal peptide for soluble expression of Leishmania infantum $\mathrm{P} 4$ nuclease in E. coli. Asian J Anim Vet Adv 7(4):326-333

Rahbarnia L, Farajnia S, Babaei H, Majidi J, Veisi K, Ahdi KS, Tanomand A (2017a) Development of a novel human scFv against EGFR L2 domain by phage display technology. Curr Pharma Des 23(13):2009-2014

Rahbarnia L, Farajnia S, Babaei H, Majidi J, Veisi K, Ahmadzadeh V, Akbari B (2017b) Evolution of phage display technology: from discovery to application. J Drug Target 25(3):216-224
Rappuoli R, Bottomley MJ, D’oro U, Finco O, De Gregorio E (2016) Reverse vaccinology 2.0: human immunology instructs vaccine antigen design. J Exp Med 213(4):469-481

Ravanfar P, Satyaprakash A, Creed R, Mendoza N (2009) Existing antiviral vaccines. Dermatol Ther 22(2):110-128

Regeimbal JM, Jacobs AC, Corey BW, Henry MS, Thompson MG, Pavlicek RL, Quinones J, Hannah RM, Ghebremedhin M, Crane NJ (2016) Personalized therapeutic cocktail of wild environmental phages rescues mice from $A$. baumannii wound infections. Antimicrob Agents Chem AAC-02877

Riedel, S. 2005. Edward Jenner and the history of smallpox and vaccination, Proc (Bayl Univ Med Cent) 1st edn, 18, (1), 21-25 Taylor \& Francis Didcot

Riley MK, Vermerris W (2017) Recent advances in nanomaterials for gene delivery review. Nanomaterials 7(5):94

Robinson KA, Beverley SM (2003) Improvements in transfection efficiency and tests of RNA interference (RNAi) approaches in the protozoan parasite Leishmania. Mol Biochem Parasitol 128(2):217-228

Rodrigues M, Hullahalli K, Palmer K (2017) CRISPR-mediated removal of antibiotic resistance genes in Enterococcus faecalis populations. FASEB J 31(1 supplement):909-3

Rouet P, Smih F, Jasin M (1994) Introduction of double-strand breaks into the genome of mouse cells by expression of a rare-cutting endonuclease. Mol Cell Biol 14(12):8096-8106

Ryther RCC, Flynt AS, Phillips Iii JA, Patton JG (2005) siRNA therapeutics: big potential from small RNAs. Gene Ther 12(1):5

Safari F, Farajnia S, Arya M, Zarredar H, Nasrolahi A (2018) CRISPR and personalized Treg therapy: new insights into the treatment of rheumatoid arthritis. Immunopharmacol Immunotoxicol 40(3):201-211

Schmelcher M, Shen Y, Nelson DC, Eugster MR, Eichenseher F, Hanke DC, Loessner MJ, Dong S, Pritchard DG, Lee JC (2015) Evolutionarily distinct bacteriophage endolysins featuring conserved peptidoglycan cleavage sites protect mice from MRSA infection. J Antimicrob Chemother 70(5):1453-1465

Scott, Cheryl (2004) Classifying vaccines. BioProcesses Inter:14-23

Semple SC, Akinc A, Chen J, Sandhu AP, Mui BL, Cho CK, Sah DW, Stebbing D, Crosley EJ, Yaworski E (2010) Rational design of cationic lipids for siRNA delivery. Nature Biotechnol 28(2):172

Shi X, Lu W, Wang Z, Pan L, Cui G, Xu J, LaBean TH (2014) Programmable DNA tile self-assembly using a hierarchical sub-tile strategy. Nanotechnology 25(7):075602

Shinefield HR (2010) Overview of the development and current use of CRM197 conjugate vaccines for pediatric use. Vaccine. 28(27): 4335-4339

Sierra JM, Ester F, Rabanal F, Vinuesa T, Viñas M (2017) An overview of antimicrobial peptides and the latest advances in their development. Expert Opin Biol Ther 17(6):663-676

Sievert DM, Rudrik JT, Patel JB, McDonald LC, Wilkins MJ, Hageman JC (2008) Vancomycin-resistant Staphylococcus aureus in the United States, 2002-2006. Clin Infect Dis 46(5):668-674

Slade BA, Leidel L, Vellozzi C, Woo EJ, Hua W, Sutherland A, Izurieta HS, Ball R, Miller N, Braun MM (2009) Postlicensure safety surveillance for quadrivalent human papillomavirus recombinant vaccine. Jama. 302(7):750-757

Steiner H, Hultmark D, Engström Å, Bennich H, Boman HG (1981) Sequence and specificity of two antibacterial proteins involved in insect immunity. Nature 292(5820):246

Sucher AJ, Chahine EB, Nelson M, Sucher BJ (2011) Prevnar 13, the new 13-valent pneumococcal conjugate vaccine. Ann Pharmacother 45(12):1516-1524

Thomas M, Lu JJ, Chen J, Klibanov AM (2007) Non-viral siRNA delivery to the lung. Adv Drug Deliv Rev 59(2-3):124-133

Trevisan M, Palù G, Barzon L (2017) Genome editing technologies to fight infectious diseases. Expert Rev Anti-Infect Ther 15(11):1001-1013

Vartak A, Sucheck SJ (2016) Recent advances in subunit vaccine carriers. Vaccines 4(2):12 
Wang J, Lu Z, Wientjes MG, Au JLS (2010) Delivery of siRNA therapeutics: barriers and carriers. AAPS J 12(4):492-503

Wang Y, Chen CH, Hu D, Ulmschneider MB, Ulmschneider JP (2016) Spontaneous formation of structurally diverse membrane channel architectures from a single antimicrobial peptide. Nature Commun 7:13535

Whitehead KA, Langer R, Anderson DG (2009) Knocking down barriers: advances in siRNA delivery. Nat Rev Drug Discov 8(2):129

Winau F, Winau R (2002) Emil von Behring and serum therapy. Microbes Infect 4(2):185-188

World Health Organization (2017) WHO guidelines on use of medically important antimicrobials in food-producing animals

Xu H, Xing J, Tang X, Sheng X, Zhan W (2019) Intramuscular administration of a DNA vaccine encoding OmpK antigen induces humoral and cellular immune responses in flounder (Paralichthys olivaceus) and improves protection against Vibrio anguillarum. Fish Shellfish Immunol 86:618-626

Yanagihara K, Tashiro M, Fukuda Y, Ohno H, Higashiyama Y, Miyazaki Y, Hirakata Y, Tomono K, Mizuta Y, Tsukamoto K (2005) Effects of short interfering RNA against methicillin-resistant Staphylococcus aureus coagulase in vitro and in vivo. J Antimicrob Chemother 57(1):122-126

Yeaman MR, Yount NY (2003) Mechanisms of antimicrobial peptide action and resistance. Pharmacol Rev 55(1):27-55
Yih WK, Nordin JD, Kulldorff M, Lewis E, Lieu TA, Shi P, Weintraub ES (2009) An assessment of the safety of adolescent and adult tetanusdiphtheria-acellular pertussis (Tdap) vaccine, using active surveillance for adverse events in the Vaccine Safety Datalink. Vaccine. 27(32):4257-4262

Zaiou M (2007) Multifunctional antimicrobial peptides: therapeutic targets in several human diseases. J Mol Med 85(4):317-329

Zarredar H, Pashapour S, Ansarin K, Khalili M, Baghban R, Farajnia S (2019) Combination therapy with KRAS siRNA and EGFR inhibitor AZD8931 suppresses lung cancer cell growth in vitro. J Cell Physiol 234(2):1560-1566

Zasloff M, Martin B, Chen HC (1988) Antimicrobial activity of synthetic magainin peptides and several analogues. Proceed Nat 1 Acad Sci 85(3):910-913

Zeng L, Wang D, Hu N, Zhu Q, Chen K, Dong K, Zhang Y, Yao Y, Guo $X$, Chang YF (2017) A novel pan-genome reverse vaccinology approach employing a negative-selection strategy for screening surface-exposed antigens against leptospirosis. Front Microbiol 8: 396

Publisher's note Springer Nature remains neutral with regard to jurisdictional claims in published maps and institutional affiliations. 